\title{
Reframing Recognition in Organizations ${ }^{1}$
}

\author{
Matthew Sowcik, Hannah Carter, and Valerie McKee ${ }^{2}$
}

Business leaders today are faced with the challenges associated with employee engagement, recruitment, and retaining top talent. According to Magnus (1981), "One answer that emerges is employee recognition programs. In many cases, properly run recognition programs can boost awareness of the organization, build employee pride, raise morale and, ultimately, increase productivity". This quote suggests an awareness for at least three and a half decades of the power associated with recognition programs. In fact, studies in the 1950s and 1960s highlighted the relationship between employee recognition and employee motivation (Brun \& Dugas, 2008).

Out of this awareness comes action. Due to the perceived importance of recognition, organizations today spend a significant amount of money on these types of programs. Employee recognition has been estimated to be $\$ 46$ billion per year globally (Garr, 2012). Other sources suggest that organizations, on average, spend approximately one percent of employee payroll on recognition efforts (Garr, 2012). This commitment to recognition programs makes sense based on recent research on the topic. On the organizational level, recognition has been associated with lower voluntary turnover, increased employee engagement, and higher organizational revenues and profitability (Brun \& Dugas, 2008; Garr, 2012; Merino \& Privado, 2015). On the personal level, recognition programs positively impact employees' psychological functioning, performance, morale, motivation, job satisfaction, happiness, and perceived organizational support (Merino \& Privado, 2015).
At this point, most organizations have some form of employee recognition program. A recent study indicates that $89 \%$ of organizations have a program, with $67 \%$ offering between three and six different recognition programs (WorldatWork, 2015). However, even with the significant financial support and number of programs offered, many organizations have significant issues with their recognition programs. The first of these issues is that employees may not be aware that the recognition program exists. In a study by Garr (2012), only 58\% of employees knew that their organization had an employee recognition program in place. Furthermore, there seems to be a significant disconnect between what senior leaders in an organization believe about the amount of recognition that occurs in their organization and the perceptions of employees. According to Garr (2012), "Nearly $80 \%$ of senior leaders believe employees are recognized at least on a monthly basis, with $43 \%$ of senior leaders stating employees are recognized weekly or more often". These findings stand in contrast to only $22 \%$ of employees who reported that their peers are recognized monthly or more often.

There are additional reasons that employee recognition programs fail, including the lack of structure enabling employees to recognize each other, difficulty selecting individuals to recognize, lack of clarity concerning program objectives, and company cultures that do not support recognition. Yet, even with all these issues, there is still opportunity to deliver programs that add value to employees' lives and to the organization overall. By utilizing Bolman and Deal's (2013) four frames (structural, human resources,

1. This document is AEC662, one of a series of the Department of Agricultural Education and Communication, UF/IFAS Extension. Original publication date December 2018. Visit the EDIS website at https://edis.ifas.ufl.edu for the currently supported version of this publication.

2. Matthew Sowcik, assistant professor; Hannah Carter, associate professor; and Valerie McKee, leadership programs coordinator; Department of Agricultural Education and Communication, UF/IFAS Extension, Gainesville, FL 32611.

The Institute of Food and Agricultural Sciences (IFAS) is an Equal Opportunity Institution authorized to provide research, educational information and other services only to individuals and institutions that function with non-discrimination with respect to race, creed, color, religion, age, disability, sex, sexual orientation, marital status, national origin, political opinions or affiliations. For more information on obtaining other UF/IFAS Extension publications, contact your county's UF/IFAS Extension office. 
political, and symbolic) to reframe this issue of recognition programs, leaders will have a better understanding of the recognition program's unique elements and provide direction regarding changes the program can undergo to be more effective.

\section{Structural Frame}

Bolman and Deal's (2013) structural frame focuses on the goals, specialized roles, and formalized relationships found within a program or organization's structure. When the structural frame is applied to an employee recognition program, it highlights the type of program, the administration of the program, the program criteria, program objectives/ goals, communication of the program, and the impact of technology on the program. The problem often associated with this frame occurs when the current structure of the employee recognition program does not fit within the current environment. By addressing these structural areas, a leader is able to create a recognition program structure that is better aligned with the organization.

\section{Structural Frame Question 1: What is the purpose of the recognition program?}

One of the most important questions when addressing the structural frame is addressing why a particular program exists or should exist. It is critical to determine the objectives and goals of the program before determining what type of program to offer or who will be responsible for administration of the program. Some of the most commonly cited objectives and goals for recognition programs include (1) appreciating years of service, (2) creating and maintaining a positive work environment, (3) creating and maintaining a culture of recognition, (4) motivating high performance, and (5) reinforcing desired behaviors (WorldatWork, 2015). Once the objectives and goals are determined, it is important to examine whether the current program is meeting those goals. Recognition programs have a life cycle and become less effective after ten years (Garr, 2012). A structure should be in place to consistently examine objectives/goals and redesign the program in order to increase employee satisfaction in the program and align the program with organizational needs.

\section{Structural Frame Question 2: What type of program fits your current environment or helps you take steps to get to the organization you want to be?}

The type of employee recognition program is extremely important when trying to achieve particular objectives and goals. The first point of clarification when examining an employee recognition program is whether it is standardized. "Standardization refers to the consistency of a program across the organization versus customization by employee type, business unit, region, function, etc." (Garr, 2012). Traditionally, employee recognition programs were grassroots efforts, often surfacing in different forms across different business departments. This structure makes employee recognition programs difficult to deliver. It is important to understand the needs of your program to understand whether you need a standardized program, partially standardized, or a customized program to meet the needs of the different employee groups.

Once leaders determine the level of standardization of the program, they can start to address what type of program to implement. Recognition programs can take on a number of different forms, and should, in order to achieve the different objectives and goals. Some of the most common employee recognition program types include length of service, performance-based, peer-to-peer recognition, and retirement. More recently, organizations have started to develop recognition programs promoting employee wellness, organizational change initiatives, significant employee personal development, and customer/client retention awards (WorldatWork, 2015).

\section{Structural Frame Question 3: What is the employee recognition program criteria and who manages the program?}

A common failing that undermines employee recognition programs is to have ambiguous criteria guiding the eligibility, selection, and recognition delivery. How the program operates is critical to the success of the program. Although best practices suggest that programs that are managed with minimum administrative efforts are more successful, the logistics of the program need to be determined ahead of time (Society for Human Resource Management, 2016). The logistics of the program include determining when the award is to be given, the selection process, the storage/ ordering of awards, delivery of awards, and the evaluation of the program. Additionally, the criteria should establish a fair program that is managed consistently year after year. Creating a recognition procedure manual is one way to pass structural information (including objectives/goals, type of programs, and criteria) along to new employees or teams who are responsible for the administration of the program.

Another important structural concern is the individual or department responsible for the program administration. Similar to organizational structure, program structure can 
be hierarchical or flat. Some organizations have success running distributed programs, where no one position is responsible for the recognition program. In this structure, the program becomes a shared responsibility among departments. This wide distribution of program oversight has advantages, including diverse perspectives and flexibility when implementing and evaluating the program's effectiveness as it applies to the particular department. On the other hand, with a lack of centralized leadership, the program is likely to be delivered differently and success is likely tied to those running the program. In cases where there is a more hierarchical approach to administration, it is common for the human resources department (or similar department/ person in the organization) to be the key administrator of the program. The question is whether you are looking for a more flexible, informal program or a program that is highly standardized across the organization.

\section{Human Resource Frame}

The Human Resource Frame, when applied to employee recognition programs, explores the impact the program has on employee motivation and satisfaction (Bolman and Deal, 2013). Problems surface when there is a perceived lack of recognition or a program does not accurately address the needs of employees, possibly leaving them unsatisfied and disengaged with their work. A focus on the Human Resource Frame has become increasingly important with the rise of the millennial generation, which requires more feedback than older generations (Willyerd, 2015). The use of employee recognition is a tool that can address the needs of this generation, keeping them engaged, productive, and loyal to the company.

\section{Human Resource Frame Question 1: Is your employee recognition program impacting employee motivation and performance?}

One of the more critical elements of a recognition program is that it influences employee performance and engagement. Recognition activities are an important extrinsic motivator to increase employee performance and engagement. Often, the difficulty is selecting between numerous types of recognition activities. For example, some of the most popular recognition activities include a simple thank-you (e.g. thank-you notes or face-to-face thank-you), an informal thank you event (like a department recognition party or dinner), public praise, gifts, monetary incentives, or formalized organization-wide celebrations.
It is important to spend some time thinking about the recognition that is provided and the long-term impact it can have on employees. There are both proponents and opponents concerning the use of financial recognition. Those in support of financial rewards suggest these financial incentives are a way to influence employee behavior. Additionally, financial recognition meets multiple human needs and serves multiple functions. Each program (depending on the goals of the program) must weigh the benefits and drawbacks of financial and non-financial incentives and the impact each has on the motivation of those being recognized.

\section{Human Resource Question 2: How is the program being communicated to recruit and retain great employees?}

One indicator of a successful program is the use of the program to recruit and retain great employees. Organizations, because of the competition for top talent, are turning more and more to recognition programs in order to recruit top talent. If all employers in a particular industry are paying about the same wage, one area of employee compensation that can stand out for your organization is the recognition program. Top talent is more likely to select an organization that provides these recognition programs believing that they will do work that gets rewarded.

However, offering a high-level recognition program is just the first step in utilizing it for recruiting top talent. In order to utilize the program, it is important to communicate the program to prospective employees. The program goals and recognition/rewards should be easily communicated so the possible hire can understand the components of the program, believes there is a high likelihood that he or she will be successful in the program, and that the recognition is of value to the prospective employee.

\section{Human Resource Question 3: How do you train managers to utilize the program effectively?}

The final question that should be explored concerning the human resource frame is whether those leading the program feel competent in running the program. Often midlevel managers are asked to manage the program for their department. Without proper training, the manager may not know the best practices; this can decrease the likelihood of program success. Instead, mistakes can be made, and the program may have a negative impact on the organizational culture and the people. Any time a change or a new program is introduced into an organization, it is 
critical that those directly managing the program receive the proper training to ensure that the program is run effectively and that the individuals feel comfortable and competent in their leadership.

\section{Political Frame}

The political frame, as it relates to recognition programs, addresses the program's power in a landscape of scarce resources (Bolman \& Deal, 2013). These resources are most often associated with time, money, and tools for program implementation. Issues can arise when power is used to promote a program that is either unjustly or ineffectively administered (Bolman \& Deal, 2013).

\section{Political Frame Question 1: What do those with power think about the recognition program?}

If a recognition program is going to be successful from the political lens, it needs to be seen as important to those who have power in the organization. This includes those who have traditional forms of power, like the positional power of senior leaders or department managers. This positional power allows these individuals the opportunity to select those who will be recognized. Additionally, power may reside in those who do not have formal positional power but engender admiration, loyalty or affection from others. Either way, those who have power are likely to set the priorities and provide resources that increase the likelihood that a program will be successful.

Two ways to better understand the importance that those in power place on the recognition program are to evaluate the time and resources these individuals allocate to the recognition program. From the perspective of time, how often senior leaders utilizes the program, how often they spend discussing the program, and whether they personally get involved with delivery of the recognition are all indicators of how the leader prioritizes the program. Additionally, the success of a program is directly related to the resources allocated to the program. In a survey conducted by SHRM/ Globoforce (2012), the data suggests that organizations which spend more than one percent of the payroll budget on employee recognition saw a positive impact on employee engagement, on financial results, and on the perception that the program helped retain employees.

\section{Political Frame Question 2: Who is being rewarded and how often?}

Exploring who in the organization is most likely to be rewarded can provide valuable information about the fairness of the program, how the program is being utilized, and potential weaknesses in the program. For example, in research conducted on employee recognition programs, senior leaders reported that they are recognized significantly more often than those at other levels of the organization. If this is the case, the program is not likely to be successful in changing or sustaining behaviors at other levels of the organization. In addition, the frequency in which particular employees are being recognized can also provide valuable information about the program. If certain employees are being rewarded more often than others, it may be important to review the program's criteria, and the managers may need to be retrained on how to use the program effectively.

\section{Political Frame Question 3: How is the program being measured and what is happening with the results?}

It can be argued that measurement of the recognition program could be a structural frame issue and that would certainly be correct. However, how the program is being measured and what is being done with the results impacts how people perceive the program's importance, and is also a major political lens issue. It is easier for a leader with power and resources to allocate time and money to a program that is perceived as having a positive impact on the organization. Every recognition program should have a way to measure and report the value it creates. In a study that was done by the Aberdeen Group (2013) called The Power of Employee Recognition, it was found that $43 \%$ of "Best-In-Class" organizations were able to measure different elements of their recognition programs compared to only $18 \%$ from all other organizations.

Referring back to the structural frame lens, it is important to utilize the objectives and goals established to drive the assessment of the program in the political frame. Some additional metrics that can also be used to measure key indicators of the program include:

- Business outcomes

- Employee participation

- Behaviors demonstrated

- Performance improvements 
After measurement occurs, it is important that the results are reported throughout the organization and that action is taken to improve upon the results and address feedback from employees.

\section{Symbolic Frame}

The symbolic frame, as it relates to recognition programs, explores the influence organizational culture has on the program. Specifically, it looks at how stories, rituals, ceremonies, and symbols are being used to ensure the program is a success (Bolman \& Deal, 2013). Problems associated with the symbolic frame occur when the culture that is established and the symbols that are communicated are not representative of the operation and outcomes of the recognition program.

\section{Symbolic Frame Question 1: Does the organization's culture support the recognition program?}

The culture of a department or organization can drive or impede the success of a recognition program. If the culture supports the recognition program, it provides an incentive for all employees to become actively involved in recognition. In cultures that highly support recognition programs, peer-to-peer recognition is more likely to occur. Peer recognition programs have a positive impact on the perceptions employees have about engagement, company values, and the company's financial results (SHRM/Globoforce, 2012).

\section{Symbolic Frame Question 2: Do the program's values align with the values of the organization?}

When a recognition program is tied to the company's values, it has a number of positive impacts on both the employee and the organizational culture. When this alignment occurs, employees feel higher satisfaction levels with work, feel more empowered, and are less likely to leave the organization. A survey by the Society for Human Resource Management and Globoforce (2012) found that strategic recognition programs, or programs that align key organizational values with recognition, increased employees' positive perception of performance reviews and contributed to higher engagement levels of employees in the organization.

When the organization's values align with the recognition program, it also directly reinforces particular desired behaviors and sets an example for others to follow. It is often a major problem with recognition programs when leaders preach about the importance of particular values, yet no one in the organization is recognized when delivering on these values. This also provides an avenue to begin to tell stories about those in the organization who have done extraordinary actions that warranted recognition. This provides clear examples that others in the organization can follow.

\section{Symbolic Frame Question 3: What are the ceremonies and/or rituals that are associated with the program?}

One of the most important elements of the recognition program is how all employees perceive the program. Employees' perception of a recognition program is significantly impacted by the ceremonies and rituals that are associated with the program. For example, the prestige of winning an Emmy is not the trophy the actor or actress wins, but the once-a-year gala that is highlighted by recognition in front of one's peers. This is true with other forms of employee recognition. Establishing ceremonies or rituals that employees can look forward to serves as an extra motivator for achieving the recognition. Even without the gala, make sure the recognition is public for two very important reasons. First, it serves as an additional reward for those who are being recognized. Second, it provides an example of the behaviors that others can work towards if they are interested in being recognized.

Of course, if the reward is small or is just a thank-you, it is still possible to establish small rituals that create meaningful moments. One example might be handing out a few lottery tickets each time someone goes above and beyond their normal work responsibilities. If employees know that the tickets are the symbol of a "thank-you" or appreciation, they will carry more significance than randomly assigning thanks in different ways.

\section{Closing}

The importance of employee recognition has been known for quite some time. However, creating successful recognition programs is still complicated based on the four frames described in this article. By addressing the questions that correspond with the four different frames (structural, human resources, political, and symbolic), those creating or managing a program can ensure they get the most out of the program. 


\section{References}

Aberdeen Group (2013). The Power of Employee Recognition. A Harte-Hanks Company. Retrieved from http:// go.globoforce.com/rs/globoforce/images/AberdeenReportNovember2013.pdf.

Bolman, L. G., \& Deal, T. E. (2013). Reframing organizations: Artistry, choice, and leadership. John Wiley \& Sons.

Brun, J. P., \& Dugas, N. (2008). An analysis of employee recognition: Perspectives on human resources practices. The International Journal of Human Resource Management, 19(4), 716-730.

Garr, S. (2012). The state of employee recognition in 2012. Oakland, CA: Bersin and Associates.

Jenkins Jr, G. D., Mitra, A., Gupta, N., \& Shaw, J. D. (1998). Are financial incentives related to performance? A metaanalytic review of empirical research. (5), 777-787.

Magnus, M. (1981). Employee recognition: A key to motivation. Personnel Journal.

Merino, M. D., \& Privado, J. (2015). Does employee recognition affect positive psychological functioning and well-being?. The Spanish journal of psychology, 18.

Shaw, J. D., \& Gupta, N. (2015). Let the evidence speak again! Financial incentives are more effective than we thought. Human Resource Management Journal, 25(3), 281-293.

SHRM/Globoforce. (2012). Employee Recognition Survey: The Business Impact of Employee Recognition. Retrieved from http://go.globoforce.com/rs/globoforce/images/ SHRMFALL2012Survey_web.pdf

Society for Human Resource Management. (2016). Managing Employee Recognition Programs. Retrieved from https://www.shrm.org/resourcesandtools/tools-andsamples/toolkits/pages/employeerecognitionprograms.aspx

Willyerd, K. (2015). Millennials want to be coached at work. Harvard Business Review, 27.

WorldatWork (2015). Trends in employee recognition. Retrieved from https://www.worldatwork.org/ adimLink?id=78679 